\title{
EXPOSIÇÃO QUE FERE, PERCEPÇÃO QUE MATA: A URGÊNCIA DE UMA ABORDAGEM PSICOSOCIOJURÍDICA DA PORNOGRAFIA DE VINGANÇA À LUZ DA LEI MARIA DA PENHA
}

\section{EXPOSURE THAT HURTS, PERCEPTION THAT KILLS: THE URGENCY OF A PSYCHO-SOCIAL-JURIDICAL APPROACH TO REVENGE PORNOGRAPHY IN THE LIGHT OF MARIA DA PENHA LAW}

\author{
Artenira da Silva e Silva \\ Universidade Federal do Maranhão - UFMA - (São Luís, MA, Brasil) \\ Rossana Barros Pinheiro \\ Universidade Federal do Maranhão - UFMA - (São Luís, MA, Brasil)
}

Recebimento: 10 jul. 2017

Aceitação: 30 jul. 2017

Como citar este artigo / How to cite this article (informe a data atual de acesso / inform the current date of access):

SILVA, Artenira da Silva e; PINHEIRO, Rossana Barros. Exposição que fere, percepção que mata: a urgência de uma abordagem psicosociojurídica da pornografia de vingança à luz da Lei Maria da Penha. Revista da Faculdade de Direito UFPR, Curitiba, PR, Brasil, v. 62, n. 3, p. 243-265, set./dez. 2017. ISSN 2236-7284. Disponível em: $<$ http://revistas.ufpr.br/direito/article/view/53834>. Acesso em: $21 \quad$ dez. $2017 . \quad$ DOI: http://dx.doi.org/10.5380/rfdufpr.v62i3.53834.

\section{RESUMO}

Este artigo apresenta uma discussão em torno da pornografia de vingança (ou exposição não autorizada da intimidade feminina na conjuntura de relacionamentos afetivos domésticos e/ou intrafamiliares), sob o enfoque da violência psicológica e moral, doméstica e de gênero. Destaca-se a naturalização das violências psicológica e moral, observada no comportamento de vítimas, agressores e operadores do direito, e evidenciada nos julgamentos sociais negativos ante a pornografia de vingança, bem como no sentimento de culpa imposto às vítimas desses julgamentos. A partir da gravidade e complexidade das relações estabelecidas entre vítimas e agressores no tipo de crime estudado, embasou-se a necessidade de aplicação da Lei Maria da Penha, considerando a aderência temática ao delito devido à centralidade das questões de gênero, modalidades de violência envolvidas e ainda da existência de garantias processuais mais protetivas. Também foram analisadas as fragilidades dos instrumentos jurídicos comumente aplicados ao objeto de investigação, como tipos penais de injúria e difamação, além da Lei Carolina Dieckmann. Para tanto foram adotados os seguintes procedimentos metodológicos: pesquisa documental, pesquisa bibliográfica e pesquisa normativa, utilizando-se de análise de conteúdo para tratamento dos dados obtidos.

PALAVRAS-CHAVE

Pornografia de vingança. Violência de gênero. Lei Maria da Penha.

\section{ABSTRACT}

This paper presents a discussion about revenge pornography (or unauthorized exposure of female intimacy in domestic and/or intrafamily affective relationships), under the focus of psychological, 
moral, domestic and gender violence. It highlights the naturalization of psychological and moral violence, expressed in the behavior of victims, perpetrators and law operators, something that is also perceived in the negative social judgments against revenge porn and in the feeling of guilt, which is socially imposed on the victims of this kind of crime. Based on the severity and complexity of the relationships established between victims and perpetrators of this type of crime under study, the need to apply the Maria da Penha Law was based on the thematic crime adherence given the centrality of gender issues, on the types of violence involved and on the existence of more protective procedural guarantees within the scope of this law. The weakness of the legal instruments, such as criminal types of libel and defamation, commonly applied to the objects of investigation, was also considered, in addition to the so-called Carolina Dieckmann Law. For this purpose, the following methodological procedures were adopted: documentary research, bibliographical research and normative research, using the content analysis procedure to handle the obtained data.

\section{KEYWORDS}

Revenge pornography. Gender violence. Maria da Penha Law.

\section{INTRODUÇÃO}

A ocorrência crescente da pornografia de vingança nos últimos anos tem chamado a atenção dos estudiosos para a necessidade da construção de novos paradigmas do conhecimento ante essa problemática do mundo globalizado. Caracterizada pelo constrangimento, humilhação e julgamentos sociais negativos, a divulgação não autorizada de material íntimo pode associar-se a diversas situações, como por exemplo, invasão de dispositivos por hackers e acesso não autorizado a banco de dados, com subsequente extorsão.

No entanto, esse fenômeno ganha ainda mais relevo quando relacionado à vingança que atinge principalmente mulheres, constituindo a esmagadora maioria de ocorrências, ante o comprometimento de um relacionamento. Avalia-se essa forma específica de exposição da sexualidade feminina que, uma vez transposta ao espaço público, enseja consequências devastadoras, considerando-se que a sociedade continua impondo às mulheres regras rígidas de condutas sociais e morais. Desse modo, avalia-se a sujeição da imagem, corpo e sexualidade da mulher, à luz da violência de gênero.

O constrangimento pessoal advindo de tal exposição é, em geral, potencializado pela sociedade, amigos, familiares e operadores do direito, gerando novos conflitos internos para a vítima e/ou potencializando outros conflitos que porventura ela possa ter, devido à assunção de responsabilidade pelo ocorrido, fenômeno reflexo da violência psicológica de gênero.

Diante de todo o exposto, é possível compreender que a pornografia de vingança é impregnada das complexas questões que circundam a violência de gênero, haja vista os pressupostos de que a relação de poder entre homens e mulheres é desigual, o que repercute diretamente no 
comportamento do agressor, na reação da sociedade perante este tipo de crime e na situação de vulnerabilidade da vítima.

Dessa forma, considera-se a Lei Maria da Penha o instrumento normativo mais adequado para o tratamento do fenômeno, haja vista a perfeita adequação temática à violência de gênero e o melhor acolhimento das vítimas, inclusive ante as ideações suicidas frequentemente observadas quando uma mulher é vítima do tipo de crime em questão. Além disso, a referida lei revela-se importante à medida que melhor protege as adolescentes, público significativo nesses casos e carente de atenção profunda, especialmente por conta do momento peculiar de desenvolvimento psicossocial no qual se encontra essa categoria de vítimas.

Diante de todo o exposto, o presente estudo direcionou-se à construção de fundamentos científicos de modo a possibilitar a compreensão da pornografia de vingança como violência de gênero, embasando a aplicação da Lei Maria da Penha aos casos afetos a essa temática e demonstrando as fragilidades dos outros instrumentos normativos comumente aplicados no Brasil em seu enfrentamento.

Tal iniciativa se justifica na medida em que promove um entendimento mais objetivo e um combate mais eficaz ante o fenômeno estudado e suas principais consequências. Observa-se que o enfrentamento do crime aludido acontece em uma conjuntura de dúvidas dos aplicadores do direito e ainda em um contexto de desenvolvimento teórico insuficiente acerca da matéria.

Para tanto foram adotados os seguintes procedimentos metodológicos: pesquisa documental, pesquisa bibliográfica e pesquisa normativa, utilizando-se de análise de conteúdo para tratamento dos dados obtidos. Tendo em vista a natureza e as finalidades da pesquisa, adotou-se como recorte temporal específico para a consideração dos dados utilizados o período de 2013 a 2017.

Quanto às fontes pesquisadas, consultaram-se livros e artigos afetos à temática da violência, legislações específicas como a Lei Maria da Penha, Código Penal, Código Civil e Lei Carolina Dieckmann. Além desses materiais, foram explorados estudos da Organização Mundial da Saúde, do Instituto Patrícia Galvão e do Instituto de Pesquisa Aplicada, todos elaborados entre os anos de 2013 e 2017. Pesquisaram-se também materiais em endereços eletrônicos, como publicações do Conselho Nacional de Pesquisa e Pós-Graduação em Direito (Conpedi) e do Google Acadêmico, além de bases de dados online como Hei online e Vlex. Quanto às decisões jurisprudenciais consideradas, destacase que foram pesquisadas no indexador de decisões jusbrasil, mecanismo que permite o acesso a decisões de tribunais localizados em todo o País. Tanto no que se refere às decisões utilizadas como no que se refere ao material consultado online, utilizaram-se como buscadores as seguintes palavras- 
chave: pornografia de vingança, revenge porn, intimidade na internet, fotos/vídeos íntimos, violência de gênero, violência psicológica na internet e violência moral na internet.

\section{POR QUE SE DEVE CONSIDERAR A PORNOGRAFIA DE VINGANÇA, ANTES DE TUDO, VIOLÊNCIA DE GÊNERO?}

Consistindo na divulgação não autorizada de conteúdo íntimo em redes sociais, a pornografia de vingança tem alcançado patamares de intensidade expressivos no mundo inteiro, inclusive no Brasil, país no qual a violência contra a mulher constitui um fenômeno em crescimento e de larga ocorrência ${ }^{1}$.

Observa-se que, embora as violências físicas sejam dotadas de maior visibilidade por conta das lesões aparentes, as violências psicológica e moral alcançam números alarmantes, correspondendo a aproximadamente 31\% das denúncias registradas na Secretaria de Políticas Públicas para Mulheres².

Tendo em vista os desfechos trágicos, como isolamento e suicídios de vítimas registrados nos últimos anos, o fenômeno tem assumido maior relevo nos âmbitos midiático e científico, chamando a atenção para a complexidade do delito.

Nesse contexto, as experiências concretas evidenciam que a liquidez característica das plataformas de internet, dotadas de alto poder destrutivo, contribuem para reafirmar violações já observadas no mundo presencial, a exemplo de outras formas de violência psicológica e moral de gênero.

Essas, quando observadas no meio virtual, não acontecem de modo formalmente distinto das práticas reais, mas reiteram e reproduzem as discriminações construídas socialmente.

Conforme afirmado por Franks (2015), a pornografia de vingança pode associar-se a variadas motivações, compreendendo desde as invasões de dispositivos por hackers com a finalidade de cometer extorsões, até a vingança ante o término de um relacionamento afetivo.

De todo modo, destaca-se principalmente a gravidade dos casos em que a dissolução do vínculo afetivo é o impulso determinante para o comportamento do agressor, haja vista o imenso

\footnotetext{
${ }^{1}$ De acordo com informações do Mapa da Violência 2015, os feminicídios no Brasil se apresentam na proporção de 4,8 para cada 100 mil mulheres. Conforme o mesmo estudo, em um ranking de 83 países avaliados pela Organização Mundial da Saúde, o Brasil ocupa o quinto lugar entre os países com maior número de homicídios femininos.

${ }^{2}$ Apesar de não deixaram marcas físicas evidentes, a violência psicológica e moral põe em risco a saúde mental e física de suas vítimas. Conforme a Organização Mundial da Saúde, a violência psicológica é a forma mais comum de agressão intrafamiliar à mulher, sendo precursora de várias outras (como o feminicídio, faceta mais extrema da violência contra a mulher). Cf. COMPROMISSO E ATITUDE. Lei Maria da Penha: A Lei é mais forte. Disponível em: <https://goo.gl/6NiNZ4>. Acesso em: 20 maio 2017.
} 
poder de sofrimento que, em geral, acompanha um rompimento amoroso, somados aos sentimentos de constrangimento, humilhação, menor valia, culpa, revolta e desespero causados pela exposição de intimidade na internet.

Diante da ocorrência dessa modalidade criminosa, observa-se que as consequências vivenciadas pela exposição pejorativa em ambiente virtual comprometem a integridade física e mental da mulher, possuindo clara configuração de violência intrafamiliar de gênero, sendo o comportamento do agressor deliberado e consciente; logo, também previsto de forma literal na Lei ${ }^{0}$ 13.104/2015, conhecida popularmente como Lei do Feminicídio.

Esse diploma normativo confere elevado destaque ao fenômeno da violência de gênero, evidenciando a faceta mais extrema desse tipo de discriminação, tipificando-a como homicídio qualificado, ou crime contra a vida.

Na Lei do Feminicídio, a tipificação penal criminaliza o assassinato de mulheres motivado pelas questões de gênero, ou a naturalização das diferenças de papéis atribuídos a ambos os sexos, no bojo de processos culturais, conforme o exposto no $\S 2^{\circ}$-A da norma.

A correlação do crime estudado com a violência de gênero também é observada de forma cristalina na Lei Maria da Penha, principal instrumento de enfrentamento do problema no Brasil. Consoante o art. 5ํ dessa lei, a violência doméstica e familiar contra a mulher consiste em ações ou omissões, baseadas no gênero, que causem morte, lesão, sofrimento físico, sexual ou psicológico, e dano moral ou patrimonial, constituindo forma de violação de direitos humanos.

Assim, as questões de gênero, retroalimentadas nas dinâmicas social e cultural, constituem o lócus discursivo para prática de violências física, psicológica, sexual, patrimonial e moral contra a mulher, previstas no art. $7^{\circ}$ da referida lei.

Em atenção à ocorrência da violência de gênero desde as épocas mais primitivas da convivência humana, bem como à sua persistência e crescente aumento de incidência no período contemporâneo, vários estudiosos lançaram mão de parâmetros e conceitos científicos na tentativa de elucidar as dimensões desse problema.

Beauvoir (1960), por exemplo, contextualizou com acuidade os principais elementos associados à construção da imagem feminina submissa ao homem, objeto de seus impulsos, desejos, posse e controle. Fatores etiológicos de cunho espiritual, cultural e sociológico ajudam a esclarecer, portanto, a diferença qualitativa de comportamentos aceitáveis para homens e mulheres nos espaços públicos e privados. 
Adicionando contornos mais precisos para essa discussão, Saffioti (1987) pontuou que é no bojo da própria dinâmica cultural que se observa essa atribuição de significados e papéis distintos conforme o sexo, havendo discriminações adensadas em um processo de naturalização.

Nesse sentido, Foucault (1999), autor contemporâneo, destacou o papel ativo dos discursos para a reafirmação das práticas sociais e sua respectiva conservação no agir dos novos sujeitos, não obstante o transcurso das gerações e seus contextos históricos.

As peculiaridades do crime de pornografia de vingança apontam para a clara persistência das questões de gênero no inconsciente coletivo, não obstante os discursos de pluralismo, tolerância e repúdio à violência de gênero.

Assim sendo, torna-se possível compreender os motivos que mais embasam os julgamentos sociais negativos sobre o comportamento das vítimas mulheres, mesmo no contexto moderno de defesa da liberdade de expressão e disposição individual do próprio corpo. Isso acontece porque a subjetividade presente no meio virtual também se encontra permeada pela moralidade e suas questões afetas de gênero (FARIA; ARAÚJO; JORGE, 2015).

Tais discriminações são observadas no comportamento do agressor, que, assumindo a condição de possuidor do corpo e da sexualidade da vítima, publica a intimidade feminina de forma deliberada e não consentida. Dessa forma, acontece a reafirmação dos discursos socioculturais que, desaprovando o comportamento permissivo da vítima, intensificam nela o sentimento de culpa e autopunição, mesmo quando está sendo vítima de violência de gênero.

A promoção do sentimento de culpa no interior das vítimas é, pois, um indicativo adicional forte de ocorrência de violência de gênero, tendo em vista que ele surge simultaneamente como reflexo e como catalisador das lesões psicológicas evidenciadas, ocasionando um consequente agravante desse tipo de crime - o castigo psicológico que a vítima se impõe emocionalmente (FERNANDES, 2015).

No caso em estudo, essa culpa censura principalmente a mulher que, de forma ousada, partilhou a sua intimidade e, além disso, escolheu erroneamente alguém para desfrutar do status de seu companheiro.

Desse modo, ocorre a justificação de toda sorte de violências com base nas escolhas e/ou atitudes da vítima. No caso da pornografia de vingança, a inversão da culpa é fomentada pelos discursos que condenam a permissão para filmar ou fotografar o corpo, bem como o exercício da sexualidade fora dos limites impostos pelo gênero. 


\section{POR QUE A PORNOGRAFIA DE VINGANÇA DEVE SER CONSIDERADA VIOLÊNCIA MORAL E PSICOLÓGICA, FATORES ETIOLÓGICOS DA LESÃO CORPORAL?}

Considerando as discriminações de gênero afirmadas pelo agressor e pela própria sociedade em casos de pornografia de vingança, a disponibilização dos contatos reais das vítimas em sites de pornografia e redes sociais é tática frequentemente adotada pelos autores do delito, facilitando perseguições por estranhos.

Diante desse quadro, inicia-se um processo de vulnerabilidade das vítimas, que, expostas a ataques físicos e virtuais, são submetidas ao assédio por desconhecidos. Dessa forma, evidencia-se a gravidade das violências praticadas nas redes sociais (CITRON; FRANKS, 2014).

Nessa discussão, Porto e Richter (2015) destacam a aptidão das plataformas virtuais para a violência on line, como o cyberbullying - prática de atitudes agressivas, ofensivas e de desestruturação emocional das vítimas.

Por conta do alcance instantâneo de milhares de pessoas, as consequências desse tipo de violência assumem dimensões até mais graves do que as agressões presenciais, haja vista a insignificância das barreiras temporais e espaciais que caracterizam os espaços cibernéticos. É o que afirmam Porto e Richter (2015).

Nesse contexto, profissionais que lidam cotidianamente com o trato da pornografia de vingança alertam para a gravidade de suas consequências, majoradas pelas circunstâncias específicas do mundo virtual, tais como a visibilidade, facilidade de propagação do conteúdo e acesso sem os limites típicos do mundo físico.

Decorrendo da característica de fluidez do mundo virtual, a dificuldade de investigação dos crimes e responsabilização de agressores contribui para o agravamento do sofrimento experimentado pelas vítimas.

Esse desconforto intenso é caracterizado pela vulnerabilidade da saúde psíquica, sendo frequentes os episódios de ansiedade, depressão, angústia, medo, tristeza, raiva, estresse, dores de cabeça e de estômago, distúrbios do sono, falta de apetite, entre outros (PORTO; RICHTER, 2015).

Aprofundando as discussões científicas em torno da relação entre violência psicológica e desequilíbrio psíquico, emocional ou psicossomático, vários autores têm construído o raciocínio no sentido de se perceber a violência psicológica de gênero e doméstica exercida de modo crônico e continuado como elemento causador de lesão corporal, tese que se encaixa perfeitamente à complexidade dos efeitos da pornografia de vingança sobre a saúde das vítimas.

Fernandes (2015), por exemplo, descreve as consequências da tortura psicológica à integridade mental, mediante a enumeração dos seguintes sintomas: transtornos, estresse e cognições 
pós-traumáticas, abuso ou dependência de substâncias, baixa autoestima, déficit em solução de problemas, suicídio, entre outros.

Dessa forma, enquanto o dano à integridade corporal frustra a incolumidade de algum elemento fisiológico da vítima, na lesão à saúde, os efeitos podem transcender a mera fisiologia, ocasionando alterações de funções do organismo e perturbação psíquica.

Apesar da urgência de compreensão e enfrentamento estatal da pornografia de vingança, haja vista o perigo que significa à vida das vítimas, as instituições brasileiras ainda caminham a passos lentos nesse sentido.

Esse atraso se dá por conta da percepção equivocada de que o principal bem jurídico tutelado nesses casos é a honra, e não a saúde, tese majoritária que desvia o foco principal da discussão e exclui a aplicação da Lei Maria da Penha, instrumento jurídico mais protetivo às vítimas e com melhor potencial de reprimenda do agressor.

Nesse sentido, destaca-se a importância dos estudos científicos multidisciplinares sobre a pornografia de vingança, de modo a instrumentalizar a incorporação de novas abordagens e procedimentos às instituições do sistema de justiça, para que estas consigam dar uma resposta efetiva ao problema.

Reforçando a percepção de que o referido crime implica lesão corporal em virtude dos desgastes físicos e emocionais que causam à saúde das mulheres, entidades não governamentais e profissionais de diversos campos do conhecimento têm atuado de forma a conscientizar gradativamente os cientistas e operadores do direito:

\footnotetext{
Na pornografia de vingança, a honra da vítima é atingida, mas como fica a saúde dela? Muitas mulheres se afastam do trabalho, da família, têm sua saúde mental arrasada. Podemos considerar a questão da lesão corporal, já que as vítimas acabam sofrendo de problemas psíquicos.

M. H., promotor de justiça titular da Coordenadoria de Combate aos Crimes Cibernéticos do Ministério Público de Minas Gerais, durante o Fórum Fale sem Medo 2014³ (grifo nosso).
}

Considerando esses perigos da exposição sexual das vítimas em casos de pornografia de vingança, vários países têm adotado medidas legislativas e administrativas no sentido de coibir o comportamento do agressor e oferecer acolhimento às vítimas.

Entre os principais Estados que já adotaram uma legislação específica para a pornografia de vingança, destacam-se os seguintes ${ }^{4}$ : Filipinas; Victória/Austrália; Canadá; Israel; Reino Unido; EUA

\footnotetext{
3 AGÊNCIA PATRÍCIA GALVÃO. Dossiê de Violência de Gênero na Internet. Disponível em: <https://goo.gl/ZGSfrb>. Acesso em: 24 ago. 2016

${ }^{4}$ Nesse sentido, conferir CYBER CIVIL RIGHTS INITIATIVE. 38 States + dc Have Revenge Porn Laws. Disponível em: <https://goo.gl/shULwB>. Acesso em: 9 maio 2017.
} 
(legislações estaduais em 16 dos 50 estados, entre os quais: Alasca, Arizona, Califórnia, Colorado, Delaware, Geórgia, Havaí, Idaho, Illinóis, Maryland, Nova Jersey, Pensilvânia, Texas, Utah, Virgínia e Wisconsin).

Tratando especialmente sobre a proteção da saúde psicológica, comprometida ante os atos de violência de gênero, outros países lançam mão de legislações condizentes com as peculiaridades do dano psicológico ${ }^{5}$. Entre esses, a Espanha adotou medidas de controle da publicidade sexista, enquanto Portugal proibiu expressamente maus tratos psíquicos ao cônjuge, conforme o disposto no Código Penal. Na França, a jurisprudência moderna reconheceu o delito de violência psicológica habitual (violence psychologique) como conduta capaz de causar depressão, perda da autoestima, pânico, doenças psicossomáticas, insônia e transtornos alimentares. Na Argentina, a legislação penal prevê modalidades da violência psicológica e simbólica, sendo que essa última consiste na perpetuação das desigualdades de gênero por meio de estereótipos que naturalizam a sujeição da mulher. No tocante à violência psicológica, a lei argentina prevê perícia realizada por profissional de gênero, de modo a elaborar laudo técnico visando materializar a violência psicológica. Em Israel, a Lei contra a Violência Doméstica tipifica o crime de stalking, entendido como perseguição ou assédio intimidante. Outros países também estabelecem esse mesmo tipo penal, como Hungria e Alemanha. No Brasil, os casos de suicídio ${ }^{6}$ registrados nos últimos anos em decorrência de vítimas se perceberem irreversivelmente expostas em redes sociais despertaram a necessidade de adaptação das instituições do sistema de justiça ante os novos desafios trazidos pelo aumento da complexidade relacional característica do processo de globalização.

\section{POR QUE URGE REVER A PERCEPÇÃO DA PORNOGRAFIA DE VINGANÇA OBSERVADA NO DISCURSO JURÍDICO MAJORITÁRIO?}

Apesar da visibilidade da pornografia de vingança no Brasil nos últimos anos, especialmente em razão de suicídios amplamente noticiados pela mídia, infelizmente ainda há muitas dúvidas e falhas quanto à aplicação da legislação pertinente aos casos, entre as quais: Código Penal, Lei Maria da Penha, Lei Carolina Dieckmann e Marco Civil da Internet.

Diante desse quadro de falta de consenso jurídico, configurando o enfrentamento insatisfatório desse crime, membros do Poder Legislativo federal tem evidenciado a necessidade de

\footnotetext{
${ }^{5}$ Conferir FERnAndeS, V. D. S. Lei Maria da Penha / O Processo Penal no Caminho da Efetividade: Abordagem Jurídica e Multidisciplinar. São Paulo: Atlas, 2015.

${ }^{6}$ Conferir a notícia BOCCHINI, L. Quem é Culpado pelo Suicídio da Garota de Veranópolis? Carta Capital, 2013. Disponível em: <https://goo.gl/RUzRLQ>. Acesso em: 20 maio 2017.
} 
estabelecer uma legislação específica para o caso. Nesse sentido, tramitam no Congresso Nacional brasileiro diversos projetos de lei alterando o Código Penal e a Lei Maria da Penha.

Do ponto de vista civil, juízes e tribunais brasileiros têm entendido majoritariamente que a pornografia de vingança fere a intimidade, a vida privada e a honra, ensejando a obrigação de indenizar por dano moral, raciocínio que revela suas falhas ante a ausência de proteção à integridade física ou psicológica da vítima, entendida, do ponto de vista científico, como integridade da saúde.

Na perspectiva criminal, o delito tem sido enfrentado mediante a tipificação como crimes contra a honra, dispostos no capítulo V do Código Penal, do art. 138 ao art. 145. Nessa tipificação, também se observa a falta de atenção à integridade da saúde, prevista no art. 129 do Código Penal, raramente aplicado.

Além da ausência de tipificação da pornografia de vingança como lesão corporal, observase ainda a falta de compreensão do delito como outros tipos penais descritos por Fernandes (2015), relacionados à violência contra a mulher, tais como constrangimento ilegal ${ }^{7}$, ameaça ${ }^{8}$ e extorsão ${ }^{9}$.

De acordo com os defensores desse enquadramento estrito, deficiente e limitado aplicado aos crimes contra a honra, esta é o principal bem jurídico lesionado quando se está diante do crime de pornografia de vingança. Entende-se por honra objetiva o status do indivíduo junto à coletividade e por honra subjetiva o status da pessoa em relação a si mesma.

No tocante à prática da pornografia de vingança, os tipos penais comumente e erroneamente aplicados aos casos concretos são os de difamação e injúria, tendo em vista que exposição não consentida lesa o aspecto subjetivo da honra, associando fato ofensivo à reputação da vítima, no caso da difamação, e macula a honra do indivíduo, ferindo sua dignidade e decoro, no caso da injúria.

A competência para julgamento dos crimes contra a honra nas modalidades injúria e difamação, especialmente no caso de divulgação de vídeos e fotos de conteúdo sexual, tem sido fixada nos juizados especiais criminais, cuja matéria e procedimentos são disciplinados na Lei 9.099/95 (Lei dos Juizados Especiais Criminais), com a nova redação dada pela Lei 11.313/06.

\footnotetext{
7 “Constrangimento ilegal Art. 146 do Código Penal - Constranger alguém, mediante violência ou grave ameaça, ou depois de lhe haver reduzido, por qualquer outro meio, a capacidade de resistência, a não fazer o que a lei permite, ou a fazer o que ela não manda.” Em uma situação de pornografia de vingança, esse delito pode ser configurado quando, por exemplo, o agressor dá ordens à vítima - e.g., a ter com ele relações sexuais -, ameaçando ferir sua honra por meio da divulgação de material íntimo.

8 “Ameaça Art. 147 do Código Penal - Ameaçar alguém, por palavra, escrito ou gesto, ou qualquer outro meio simbólico, de causar-lhe mal injusto e grave.” Nesse caso, a remissão a um mal injusto e grave, como a divulgação de fotos em um site de pornografia, por exemplo, faz a diferenciação entre a ameaça e o constrangimento ilegal.

9 "Extorsão Art. 158 do Código Penal - Constranger alguém, mediante violência ou grave ameaça, e com o intuito de obter para si ou para outrem indevida vantagem econômica, a fazer, tolerar que se faça ou deixar de fazer alguma coisa.” Nesse caso, o agressor exige vantagem econômica, sob pena de expor a intimidade da vítima.
} 
Nesses casos, há a possibilidade de acordo e renúncia ao direito de queixa ou de representação, demonstrando mais uma vez a fragilidade desse sistema punitivo ante a magnitude do delito considerado, tendo em vista a desproporção dos danos causados à mulher e a efetiva proteção dela, pois a ação penal depende exclusivamente de representação da ofendida, não abrangendo, além disso, acompanhamento multidisciplinar dela ou do agressor. Por fim, as penas correspondem a delitos de menor potencial ofensivo.

Conforme o disposto no art. 62 da Lei 9.099/95, o processo orientar-se-á pelos critérios da oralidade, informalidade, economia processual e celeridade, tendo em vista, sempre que possível, a reparação dos danos sofridos pela vítima e a aplicação da pena não privativa de liberdade.

Chama-se atenção para a falta de correspondência entre os objetivos legais dos juizados criminais, solução de lides simples em um menor intervalo de tempo, e a pornografia de vingança, crime complexo que demanda acompanhamento constante das vítimas e medidas jurídicas específicas.

Muito embora a matéria seja recente e ainda careça de interpretação mais refinada e uníssona por grande parte dos tribunais do País, o enquadramento da pornografia de vingança apenas como crime contra a honra ou ilícito cível gerador da obrigação de indenizar, desconectado da violência de gênero que a caracteriza, tem sido a tendência predominante nos tribunais superiores e em alguns tribunais estaduais, conforme se pode observar nos seguintes julgados:

APELAÇÃO CÍVEL. RECURSO ADESIVO. AÇ̃̃O INDENIZATÓRIA. EXPOSIÇÃO DE FOTOS ÍNTIMAS NA INTERNET. OFENSA À INTIMIDADE E PRIVACIDADE. DANO À IMAGEM CONFIGURADO. VERBA INDENIZATÓRIA MAJORADA. [...] Ainda que a autora tenha ingenuamente confiado em seu então namorado, deixando-se fotografar em posições eróticas, houve quebra de confiança da parte do réu, que divulgou as imagens por motivo de vingança, conduta esta que está a merecer firme reprovação ética e jurídica. [...]. BRASIL. Tribunal de Justiça do Rio Grande do Sul. Apelação Cível No 70065184418, Nona Câmara Cível. Relator: Eugênio Facchini Neto. Julgado em 26/08/2015. Disponível em: <https://goo.gl/4CGFJQ>. Acesso em: 2 jul. 2017.

Na maioria absoluta das decisões proferidas por tribunais brasileiros, entre eles o Tribunal de Justiça do Estado do Maranhão (TJMA), observa-se o entendimento majoritário no sentido de condenação do agressor ao pagamento de danos morais.

Ainda assim, observa-se a percepção da gravidade dos danos causados à vítima em algumas decisões, embora não se faça uma correlação com a violência de gênero, prevista na Lei Maria da Penha. Nesse sentido, observe-se outra decisão proferida pelo TJRS:

APELAÇÃO CÍVEL. RESPONSABILIDADE CIVIL. AÇÃO DE INDENIZAÇÃO POR DANOS MORAIS. EXPOSIÇÃO DE FOTO ÍNTIMA EM REDE SOCIAL SEM AUTORIZAÇÃO [...] DANO MORAL IN RE IPSA [...] Dano moral caracterizado. Ato 
ilícito indenizável consistente na exposição sem autorização de foto íntima em rede social de grande porte, sendo impossível precisar o tamanho da exposição sofrida pela autora. Dano da espécie in reipsa. Dispensada a comprovação efetiva do dano, sendo suficiente a comprovação do ato ilícito e nexo de causalidade [...]. (Grifos nossos). BRASIL. Tribunal de Justiça do Rio Grande do Sul. Apelação Cível no 70052257532. Nona Câmara Cível. Relator: Iris Helena Medeiros Nogueira. Julgado em 12/12/2012. Disponível em: $<$ https://goo.gl/zLwJwr>. Acesso em: 2 jul. 2017.

Em outros casos percebe-se, lamentavelmente, que conceitos machistas e patriarcais introjetados e naturalizados, inclusive nos julgadores, concorrem para a interpretação de que a vítima colaborou com a prática do ato, sendo, portanto, considerada corresponsável por suas consequências, o que interfere diretamente na arbitragem dos danos morais, como se pode observar em decisão do TJMG:

APELAÇÃO CÍVEL - CORPO FEMININO - FOTOS DE PARTES INTIMAS DIVULGAÇÃO PELA INTERNET - AUTORIA INCERTA - DANOS MORAIS DEVER DE INDENIZAR - PARTICIPAÇÃO EFETIVA DA VÍTIMA - INDENIZAÇÃO DIMINUÍDA.

- As fotos em posições ginecológicas que exibem a mais absoluta intimidade da mulher não são sensuais. Têm definição mais amarga.

- A postura de quem fragiliza o conceito de moral pode autorizar avaliação condizente com essa postura.

- Havendo dúvidas quanto a origem da divulgação de fotos tiradas por webcam não se pode fixar um culpado.

- Vítima que participa de forma efetiva e preponderante para a consumação do fato tem de ser levado em consideração na fixação da condenação (grifos nossos). BRASIL. Tribunal de Justiça do Estado de Minas Gerais. 16 ${ }^{a}$ Câmara Cível. Apelação Cível no 1.0701.09.250262-7/001. Relator: José Marcos Rodrigues Vieira Julgado em 23/07/2015. Disponível em: <https://goo.gl/K2bzGn>. Acesso em: 8 jul. 2017.

Dessa forma, percebe-se que nem mesmo as decisões jurídicas escapam dos conceitos machistas e de estereótipos culturais que permeiam as questões de gênero, vigentes socialmente, o que explica a transposição iatrogênica e tecnicamente hipossuficiente de julgamentos morais e não éticos e/ou bioéticos para o direito.

Tais julgamentos, distantes de parâmetros científicos transdisciplinares, fragilizam ainda mais a proteção das vítimas nesses casos, potencializando os danos a elas já causados, configurando uma segunda ordem de violência tão ou mais grave e cruel que a primeira: a institucional.

Na maioria esmagadora dos casos, apesar da percepção em torno dos gravíssimos danos causados à vítima, os tribunais continuam tipificando a pornografia de vingança meramente como crime contra a honra, especialmente como injúria e difamação comuns, desconectando-a de sua configuração clara de violência de gênero, em geral, intrafamiliar.

Predomina assim o entendimento simplista, reducionista e tecnicamente insuficiente para a compreensão e tratamento do delito em tela, como pode ser exemplificado na decisão abaixo, proferida pelo TJPR: 
PENAL. APELAÇÃO. CRIMES DE INJÚRIA E DE DIFAMAÇÃO. ARTS. 139 E 140 DO CÓDIGO PENAL. AGENTE QUE POSTA E DIVULGA FOTOS ÍNTIMAS DA EXNAMORADA NA INTERNET. IMAGENS E TEXTOS POSTADOS DE MODO A RETRATÁ-LA COMO PROSTITUTA EXPONDO-SE PARA ANGARIAR CLIENTES E PROGRAMAS [...] Comete os crimes de difamação e de injúria qualificadas pelo emprego de meio que facilita a sua propagação $\neg$ arts. 139 e 140, c.c. 141, II do CP o agente que posta na Internet imagens eróticas e não autorizadas de ex-namorada, bem como textos fazendoa passar por prostituta. BRASIL. Tribunal de Justiça do Paraná. Apelação Criminal no 756.367-3 (NPU da $4^{\text {a }}$ vara criminal da comarca de Maringá. Interessado: Ministério Público. Relator: juíza Lilian Romero.

Em sentido diametralmente oposto, os estudos doutrinários avançam gradativamente, de modo a fornecer subsídios científicos para o enquadramento da pornografia de vingança como violência contra a mulher ${ }^{10}$. Nesse sentido, destacam-se por conta de seus entendimentos transdisciplinares e em conformidade com a complexidade e especificidade características da violência de gênero, considerando-se em especial sua modalidade intrafamiliar.

De todo modo, observa-se ainda como entendimento majoritário o mais superficial, no sentido do enquadramento estrito da pornografia de vingança como crime contra a honra, deixandose de dar a devida atenção às lesões à saúde psicológica e à integridade física da vítima.

Além das possibilidades de tipificação da pornografia de vingança como crime contra a honra ou violência psicológica contra a mulher, no Brasil existe também a possibilidade de enquadramento da conduta no rol dos crimes cibernéticos, previstos na Lei 12.737/2012, popularmente conhecida como Lei Carolina Dieckmann.

O referido diploma legislativo foi promulgado em um contexto de discussão acerca das garantias individuais ante a publicação de fotos íntimas não autorizadas da atriz Carolina Dieckmann, que, ante as ameaças de extorsão, recusou-se a pagar a quantia exigida por hackers, que publicaram o conteúdo íntimo na internet.

Dessa forma, a Lei Carolina Dieckmann refletiu o momento de complexidade oriundo da emergência de novos sistemas de gerenciamento da informação e disposição da intimidade, característicos do processo de globalização.

De acordo com a referida lei, são considerados crimes cibernéticos: invasão de dispositivo informático alheio, de qualquer espécie, com a finalidade de obter, adulterar ou destruir dados ou

\footnotetext{
${ }^{10}$ Conferir os seguintes estudos científicos: BUZZI, V. M. Pornografia de Vingança: Contexto Histórico-Social e Abordagem no Direito Brasileiro. Florianópolis: Empório do Direito, 2015. MORELLI, J.; AMIRTON, A.; MEIRELLES, F. S. L. Violência de gênero no século XXI: a pornografia de vingança. Revista da EMERJ, Rio de Janeiro, v. 18, n. 71, p. 88-93, nov./dez. 2015; VALENTE, M. G. et al. O corpo é o código: estratégias jurídicas de enfrentamento ao revenge porn no brasil. InternetLab: São Paulo, 2016.
} 
informações; instalação de qualquer vulnerabilidade ao dispositivo informático, com o fim de obter uma vantagem ilícita; produção, oferecimento, distribuição, venda ou difusão de dispositivo ou programa de computador com o intuito de permitir a invasão de dispositivo informático ou a instalação de vulnerabilidades, entre outros.

No entanto, também é possível identificar fragilidades nos enunciados do diploma legislativo, especialmente no tocante à definição de “dispositivo informático”, não sistematizado de forma ampla e clara, considerando-se que há uma infinidade de dispositivos existentes capazes de armazenar dados sujeitos à violação.

Da mesma forma, observam-se problemas na escolha do termo "invadir”, que não abrange o ato de ter acesso a conteúdo íntimo sem invasão, como no caso de compartilhamentos de vídeos e fotos no aplicativo WhatsApp (SILVA; SILVA, 2014).

Além da Lei Carolina Dieckmann, no Brasil também é possível registrar o Marco Civil da Internet como norma alinhada aos direitos no contexto da sociedade da informação. Promulgado no ano de 2014, o referido diploma regulou o uso da internet mediante o estabelecimento de princípios, deveres e garantias aos usuários da rede, determinando também as obrigações estatais pertinentes.

Não obstante o entendimento majoritário no sentido de tipificar a pornografia de vingança como crime contra a honra, felizmente observam-se também argumentos mais razoáveis no sentido de seu enquadramento na Lei 11.340/2006, popularmente conhecida como Lei Maria da Penha, como violência psicológica e/ou moral.

\section{POR QUE A LEI MARIA DA PENHA É O INSTRUMENTO JURÍDICO MAIS ADEQUADO AO PROCESSAMENTO E JULGAMENTO DO CRIME DE PORNOGRAFIA DE VINGANÇA?}

No contexto da pornografia de vingança, a violência psicológica contra a mulher torna-se tão devastadora quanto a agressão física ou até mais grave que esta, haja vista o alto potencial de dano e facilidade de compartilhamento de vídeos e imagens com conteúdo sexual. Tal gravidade tem despertado nos tribunais a ideia de que a vítima tem direito ao esquecimento de recordações que lhe causem dor ou sofrimento emocional, como material íntimo divulgado na internet, de fácil acesso e permanente exposição.

A Lei foi promulgada no contexto do combate à violência doméstica e familiar praticada contra a mulher, tendo em vista o valor atribuído à instituição familiar, núcleo base do Estado, principalmente visando proteção integral à dignidade da mulher, cujos direitos fundamentais são assegurados de modo que se alcance a igualdade de direitos em relação ao homem e possam deles 
gozar independentemente de classe, raça, etnia, orientação sexual, renda, cultura, nível educacional, idade ou religião. Ao dispor no seu artigo $7^{\circ}$ sobre as formas de violência doméstica e familiar contra a mulher, reproduz a Convenção Interamericana para Prevenir, Punir e Erradicar a Violência contra a Mulher, também conhecida como “Convenção de Belém do Pará”, da qual o Brasil é signatário.

Nessa discussão, Fernandes (2015) chama a atenção para a importância do combate à violência contra a mulher, tendo em vista suas proporções e gravidade. De acordo com a referida autora, a violência contra a mulher não se trata de uma questão privada, mas sim de um grave problema de saúde pública, que acomete milhares de mulheres no mundo todo, gerando comprometimentos de ordem física e psíquica muitas vezes irreparáveis. Além disso, a violência de gênero também implica reflexos nocivos nos filhos e filhas das vítimas, na medida em que esses tendem a repetir os padrões de comportamento aos quais são expostos, em qualquer de suas modalidades, quer seja deixando-se sujeitar a violências futuras ou ainda as reproduzindo em suas relações interpessoais (FERNANDES, 2015).

Dias (2011) anota que o legislador infraconstitucional se preocupou em definir criteriosamente os tipos de violência contra a mulher, uma vez que a precisão dos termos e a previsão legal das condutas se coadunam com o princípio da legalidade, vetor de todos os ramos do direito. Seguindo a mesma linha de raciocínio, Fernandes (2015) pontua que, com a Lei Maria da Penha, houve o rompimento do processo penal tradicional, de forma a proteger a mulher, garantindo-se a efetividade da tutela jurisdicional, tendo em vista a releitura dos papéis tradicionais atribuídos aos atores do sistema de justiça. Assim, o delegado de polícia presta o socorro imediato à vítima, devendo zelar pela sua proteção, enquanto o promotor de justiça assume a função de interventor na realidade social; o juiz, contrariando os limites processuais do princípio da inércia, pode adotar de ofício medidas protetivas, e o acusado, por sua vez, é alguém que pode ser compelido a modificar seu padrão comportamental (FERNANDES, 2015).

De acordo com o art. $5^{\circ}$ da Lei Maria da Penha, violência doméstica e familiar contra a mulher é qualquer ação ou omissão baseada no gênero, que lhe cause morte, lesão, sofrimento físico, sexual ou psicológico e dano moral ou patrimonial. Dessa forma, observa-se a eleição do conceito gênero para a tipificação desse tipo de violência.

O rol de atitudes caracterizadas como violência contra a mulher foi ampliado pela Lei Maria da Penha, que, além de considerar como violência doméstica as agressões que incidem sobre o corpo da mulher, tipifica também as agressões revestidas de fatores psicológicos, morais e patrimoniais, enumeradas no artigo $7^{\circ}$ da mencionada lei. Nessa discussão, Fernandes (2015) pontua que a violência física consiste em ofender a integridade ou saúde corporal da mulher, provocando danos à saúde ou 
integridade física, deixando ou não marcas aparentes. Conforme a autora, a gravidade das lesões identifica vias de fato, lesão corporal - entendida como dano à integridade física e mental - tortura, homicídio, entre outros.

Por sua vez, a violência psicológica marca o início do processo de dominação do agressor sobre a vítima, mediante controle e rebaixamento. Manifestada de maneira sutil em seus estágios iniciais, enseja o controle emocional da vítima. Não consiste em um ato isolado, mas em um padrão de relacionamento, de crimes em concurso, cíclica e infinitamente repetidos das mais diversas formas. As consequências desse tipo de violência são graves e variadas, como: dano emocional, diminuição da autoestima, prejuízo do pleno desenvolvimento, degradação da vítima, controle de suas ações, comportamentos, crenças e decisões (FERNANDES, 2015).

Além dessas modalidades, a Lei também se atenta à violência sexual, imposição da prática de atos sexuais contra a vontade da mulher lesada e à violência patrimonial, subordinação daquela ao agressor mediante a privação de recursos econômicos, por exemplo.

Por fim, a Lei Maria da Penha também dispensou tratamento à violência moral, conduta que causa sofrimento por meio de calúnias, injúrias ou difamações, atingindo de forma muito agressiva as vítimas, tendo em vista a rigidez com que a sociedade valora a moralidade feminina.

Nesse ponto, destaca-se mais uma faceta da pornografia de vingança, entendida como exposição íntima não autorizada da vítima, cujo comportamento moral tende a ser reprovado socialmente. Essa violência moral prevista na Lei Maria da Penha, caracterizada como violência de gênero, revela-se muito mais adequada aos delitos em discussão do que a mera ofensa moral indiferenciada prevista no Código Penal.

Conforme o entendimento de Silva e Alves (2016), existem fundamentos sólidos para a criminalização da violência psicológica, manifestação da violência de gênero, como crime de lesão corporal à saúde, com base no caput e $\S 9^{\circ}$ do art. 129 do Código Penal brasileiro, combinado com o art. $7^{\circ}$, II, da Lei 11.340/2006. Os autores ressaltam que, tanto no âmbito de atuação do Ministério Público quanto no do Poder Judiciário ainda é incomum a condenação do agressor unicamente com base na prática de violência psicológica doméstica e de gênero. Essas agressões cíclicas e crônicas implicam comprometimento significativo da autoestima, atitudes, desenvolvimento e crenças da mulher, causando constrangimento, isolamento, limitação ao direito de ir e vir e, portanto, comprometimento da saúde psicológica da vítima.

Nessa discussão, merece destaque a denúncia oferecida pelo Ministério Público de São Paulo no ano de 2012, raciocínio jurídico em que as lesões corporais e desequilíbrio da saúde da vítima figuraram como principais argumentos para a denúncia do agressor, autor de violência psicológica 
utilizando-se de meios virtuais. Elaborada no ano de 2012, a peça processual apresenta uma tese inovadora no tocante à compreensão transdisciplinar da violência de gênero, violências dela decorrentes e seus efeitos reais na vida das vítimas. Consequentemente, observa-se a proteção efetiva da vítima mediante a combinação do tipo penal de lesão corporal com as disposições da Lei Maria da Penha:

[...] O denunciado, prevalecendo-se das relações domésticas, ofendeu a saúde da sua exesposa [...] causando-lhe lesão psíquica de natureza grave, com incapacidade para as ocupações habituais por mais de trinta dias e debilidade da função psíquica, conforme o laudo pericial de fls. 231/240. [...] As ameaças e ofensas à esfera psíquica da vítima foram praticadas pelo denunciado através de emails [...], mensagens de celular, bem como páginas na internet. [...] No ano de 2008, as ameaças e perseguições por parte do denunciado tornaram-se mais intensas, fato que motivou a lavratura de vários boletins de ocorrência e de atas notariais pela ofendida, bem como a concessão de medidas protetivas de urgência.[...] Desse modo, a vítima foi diagnosticada com estresse pós-traumático (CID 10 F43.1), [...] Portanto, concluímos que a examinada sofreu lesão corporal por ofensa à saúde, e de natureza grave (por lesão permanente de caráter psíquico).[...] Com efeito, extrai-se do mencionado laudo pericial que a ofensa à saúde psíquica da vítima resultou em incapacidade para as ocupações habituais por mais de trinta dias e em debilidade da função psíquica, pois o transtorno de estresse pós-traumático que a acomete perdura há mais de um ano [...].Diante do exposto, o Ministério Público denuncia L.E.A.B como incurso nos artigos 129, parágrafo $1^{\circ}$, I e III, c.c artigo 129, parágrafo 10 do Código Penal, com incidência das disposições da Lei $\mathbf{n}^{0}$ 11.340/06 [...]. (grifos nossos).

BRASIL. Ministério Público do Estado de São Paulo. Ação Penal 003848838.2011.8.26.0002. Inquérito Policial 239/2011 - $3^{\text {a }}$ Delegacia de Defesa da Mulher. Disponível em: <https://goo.gl/VxMk8L>. Acesso em: 1 maio 2017.

Observa-se assim que a violência doméstica de gênero ocorre de modo cíclico, reiterado e crônico, e tem como autor alguém de forte valoração afetiva, quer pretérita quer presente, para a vítima, o que por sua vez potencializa o sentimento de culpa da vítima e dificulta que ela obtenha apoio social familiar ou de amigos para denunciar a violência sofrida, sob o argumento de que ela estaria, por exemplo, “prejudicando o pai de seus filhos”. Sem apoio social e ainda comumente se sentindo culpada por sua vinculação com o agressor, a vítima adia ao máximo a busca de proteção pelo sistema de justiça, restando, assim, evidenciados a complexidade e o poder destrutivo desse tipo de violência e suas consequências.

A violência psicológica constitui uma modalidade de violência doméstica de gênero que merece especial atenção, uma vez que, quer ocorra em meio a outros tipos de violência, quer ocorra isoladamente, implica sofrimento intenso para as vítimas, que comumente a descrevem como mais doloroso que a violência física, por exemplo. Logo, dependendo de seu poder destrutivo e/ou consequências para a vítima, deve ser entendida como lesão à saúde, haja vista a necessidade de interpretações transdisciplinares para descrever esse elemento (SILVA; ALVES, 2016). Nesse sentido, Aníbal Bruno (1976) afirma que as perturbações ao psiquismo também são lesões corporais, 
ou danos à saúde, abrangendo estados de inconsciência ou insensibilidade determinados pelo uso de anestésicos ou inebriantes. Além disso, também são observados depressão física ou mental, desmaios, estados confusionais e outras manifestações de perturbação nervosa ou psíquica, sendo indiferente para a configuração de ameaça à saúde a produção de dor meramente física, uma vez que a dor psíquica também é mensurável e periciável (BRUNO, 1976).

Assim, observa-se que, nos casos de pornografia de vingança, são relacionadas várias condutas agressivas, entre as quais: violência psicológica (lesão à saúde), violência patrimonial (necessidade de trocar de endereço e emprego, além do custeamento de tratamentos médicos, psicológicos e honorários advocatícios) e violência moral (injúria e difamação), não obstante o entendimento superficial e supressor da magnitude da dor causada por esse tipo de delito, presente na prática cotidiana de tribunais e delegacias.

Quanto à pornografia de vingança, Lins (2015) destaca que a correspondência da conduta com a violência psicológica poderia implicar soluções, haja vista a maior proteção trazida pela maior abrangência semântica e normativa do tipo penal, ao contrário do enquadramento limitado comumente adotado pelo sistema de justiça. Para tanto, faz-se necessário que os operadores do direito adquiram conhecimentos transdisciplinares, de modo que possam caracterizar a pornografia de vingança como violência de gênero doméstica. Desse modo, deverão ser observados os seguintes elementos caracterizadores nos crimes de pornografia de vingança: relação de poder baseada no gênero; qualquer um dos planos de violência previstos na lei, seja física, psicológica, patrimonial, moral ou sexual; unidade doméstica, da família ou em razão de qualquer relação de afeto (SILVA; ALVES, 2016).

Nessa discussão, a caracterização da pornografia de vingança como violência psicológica teria consequências jurídicas importantes, como o atendimento humanizado, acompanhamento da vítima por equipe interdisciplinar, indisponibilidade da ação penal e possibilidade de aplicação de medidas protetivas pelo juízo competente, além de acompanhamento de vítima e agressor por diversas instituições, tendo em vista a gravidade da violência.

Além da maior adequação ao fim de proteger a saúde mental da mulher vítima de pornografia de vingança, destaca-se também o maior acolhimento quanto ao prosseguimento da ação penal em caso de aplicação da Lei Maria da Penha, tendo em vista a indisponibilidade da ação, qualificação que opera o compartilhamento de interesses do Estado e da vítima. Nessa discussão, o problema central não consiste na ausência de preenchimentos legais para enquadramento da pornografia de vingança na Lei Maria da Penha, como manifestação de violência psicológica, tendo em vista que uma parte expressiva dos casos acontece em razão de relação de afeto preexistente entre as partes. 
A problemática consiste na falta de compreensão do caráter da pornografia de vingança como lesão ou violência à saúde psicológica da vítima, percepção que não é ainda observada em peças jurídicas produzidas por advogados, membros do Ministério Público e Poder Judiciário. Essa é uma das conclusões registradas no livro O Corpo é o Código: Estratégias Jurídicas de Enfrentamento ao Revenge Porn no Brasil, que, compreendendo pesquisas documentais e de campo, contribuiu significativamente para a elucidação da pornografia de vingança, ante as dificuldades institucionais no seu enfrentamento:

O que percebemos é que a Lei Maria da Penha não tem sido mobilizada pelos/as advogados/as ou pelo Ministério Público, o que surpreende, uma vez que em grande parte dos casos que analisamos era identificável algum tipo de relação entre as partes. Quando entramos em campo, não achamos que essa seria uma grande questão: parecia-nos que o tema de que tratávamos seria claramente um caso de violência psicológica ou mesmo moral prevista na Lei Maria da Penha, quando a relação entre as partes pudesse ser verificada. Foi surpreendente, assim, que não se tenha verificado a mesma posição por parte dos atores e atrizes do sistema de Justiça - não estamos falando de casos em que magistrados negaram a aplicação da lei, e sim de ela nem aparecer dentre os pedidos da parte acusadora (VALENTE et al., 2016, grifo nosso).

Dessa forma, observa-se a necessidade de investigação dos elementos que obstam o reconhecimento da pornografia de vingança como violência psicológica contra a mulher, de modo a observar a partir disso os desdobramentos possíveis na efetividade resultante da divisão de competências entre juizado criminal e vara da mulher.

Nesse sentido, Santos (1996) problematiza a formação legalista e simplista dos profissionais de direito brasileiros, destacando sua inaptidão ante a complexidade dos conflitos sociais trazidos à demanda do sistema de justiça, ainda ancorado no determinismo, positivismo e racionalismo científico, elementos não condizentes com os paradigmas dos conflitos atuais.

Pautando-se no paradigma jurídico-dogmático, esse instrumental teórico se funda na eliminação de elementos extranormativos no momento de aplicação das normas, na autonomia do direito, na separação entre o direito e suas finalidades sociais e na limitação dos problemas jurídicos aos autos do processo, sem atenção à sua ligação com a realidade (SANTOS, 1996).

Dessa maneira, Santos (1996) pontua que essa cultura normativista, técnico-burocrática e positivista impressa nos operadores do direito a partir da uma formação jurídica deficiente, constitui barreira para a transformação das instituições de justiça, urgente por conta da globalização, aumento das desigualdades e despolitização do social.

Nessa perspectiva, também atenta às deficiências da formação dos operadores do direito, Fernandes (2015) destaca as consequências dessas deficiências diante do enfrentamento à violência 
de gênero, entre as quais a revitimização e/ou violência institucional, oriunda da imperícia de quem possui o dever legal de agir e proteger.

\section{CONCLUSÕES}

Consistindo na divulgação não autorizada de fotos, mensagens, gravações ou vídeos com conteúdo sexual, a pornografia de vingança pode estar associada a motivações diversas, apresentando maior escala de gravidade sob a forma de represália ante o término de um relacionamento íntimo.

Conforme foi discutido no presente trabalho, a caracterização da violência de gênero está claramente presente no comportamento do agressor, em julgamentos sociais negativos ante a exposição da sexualidade feminina e nas situações de fragilidade da vítima. Assim, diante da prática da pornografia de vingança, torna-se urgente a aplicação de instrumentos jurídicos centrados na compreensão do conceito de violência de gênero, como a Lei Maria da Penha.

Atualmente a maior parte dos juristas e tribunais brasileiros, incluindo-se o TJMA, tem interpretado a pornografia de vingança meramente como atentado à honra objetiva e subjetiva, fato gerador da obrigação de indenizar regulado pela Lei dos Juizados Especiais e pela Lei de Crimes Cibernéticos, descaracterizando a complexidade do referido fenômeno, bem como invisibilizando seu real poder de dano e consequências para a vítima.

Avaliando os pilares desse entendimento majoritário, o presente estudo demonstrou que tal percepção se revela ineficiente e inadequada ao tratamento da pornografia de vingança, na medida em que tutela tão somente a honra, ignorando por completo as graves lesões causadas à saúde da vítima, inerentes à violência psicológica continuada perpetrada por alguém de intensa vinculação afetiva com a vítima, quer no passado, quer no presente.

Também se discutiram as principais fragilidades da Lei Carolina Dieckmann no que tange ao combate efetivo do delito em questão, como a ausência de tutela específica da dignidade sexual feminina e a falta de sua aplicabilidade aos crimes praticados mediante o compartilhamento do material em questão.

Consideradas as deficiências da percepção observada de modo predominante no discurso jurídico brasileiro acerca da pornografia de vingança, pontua-se a Lei Maria da Penha como a legislação mais adequada para seu enfrentamento, dada a complexidade do fenômeno, tendo em vista sua correspondência com as formas de violência previstas na lei 11.340/2006, potencializadas por ocorrerem em ambiente virtual. 
Conclui-se, assim, que o processamento e julgamento da pornografia de vingança à luz da Lei Maria da Penha favorece uma melhor compreensão da abrangência do fenômeno, possibilitando ainda a modificação substancial da natureza da ação penal a ser proposta, bem como a atribuição de novos significados aos papéis de todos os atores do sistema de justiça quando estiverem diante da gravidade e complexidade do fenômeno estudado no presente artigo.

\section{REFERÊNCIAS}

AGÊNCIA PATRÍCIA GALVÃO. Dossiê de violência de gênero na internet. Disponível em: $<$ https://goo.gl/ZGSfrb>. Acesso em: 24 ago. 2016.

BEAUVOIR, S. O segundo sexo: fatos e mitos. São Paulo: Difusão Europeia do Livro, 1960.

BOCCHINI, L. Quem é culpado pelo suicídio da garota de Veranópolis? Carta Capital, 2013. Disponível em: <https://goo.gl/RUzRLQ>. Acesso em: 20 maio 2017.

BRASIL. Lei 11.340, de 7 de agosto de 2006. Cria mecanismos para coibir a violência doméstica e familiar contra a mulher, nos termos do § 8o do art. 226 da Constituição Federal, da Convenção sobre a Eliminação de Todas as Formas de Discriminação contra as Mulheres e da Convenção Interamericana para Prevenir, Punir e Erradicar a Violência contra a Mulher; dispõe sobre a criação dos Juizados de Violência Doméstica e Familiar contra a Mulher; altera o Código de Processo Penal, o Código Penal e a Lei de Execução Penal; e dá outras providências. Disponível em: <https://goo.gl/mzfNI>. Acesso em: 2 jul. 2017.

BRASIL. Lei 12.737, de 30 de novembro de 2012. Dispõe sobre a tipificação criminal de delitos informáticos; altera o Decreto-Lei no 2.848, de 7 de dezembro de 1940 - Código Penal; e dá outras providências. Disponível em: <https://goo.gl/PeDjn>. Acesso em: 2 jul. 2017.

BRASIL. Ministério Público do Estado de São Paulo. Ação Penal 0038488-38.2011.8.26.0002. Inquérito Policial 239/2011 - $3^{\text {a }}$ Delegacia de Defesa da Mulher. Disponível em: <https://goo.gl/kPoiSw>. Acesso em: 1 maio 2017.

BRASIL. Tribunal de Justiça do Estado de Minas Gerais. 16a Câmara Cível. Apelação Cível $\mathbf{n}^{\mathbf{0}}$ 1.0701.09.250262-7/001. Relator: José Marcos Rodrigues Vieira. Julgado em 23/07/2015. Disponível em: <https://goo.gl/K2bzGn>. Acesso em: 8 jul. 2017.

BRASIL. Tribunal de Justiça do Rio Grande do Sul. Nona Câmara Cível. Apelação Cível No 70065184418. Relator: Eugênio Facchini Neto. Julgado em 26/08/2015. Disponível em: $<$ https://goo.gl/4CGFJQ>. Acesso em: 2 jul. 2017.

BRASIL. Tribunal de Justiça do Rio Grande do Sul. Nona Câmara Cível. Apelação Cível $\mathbf{n}^{\mathbf{0}}$ 70052257532. Relator: Iris Helena Medeiros Nogueira. Julgado em 12/12/2012. Disponível em: $<$ https://goo.gl/zLwJwr>. Acesso em: 2 jul. 2017.

BRUNO, A. Crimes contra a pessoa. Rio de Janeiro: Editora Rio, 1976. 
BUZZI, V. M. Pornografia de vingança: contexto histórico-social e abordagem no direito brasileiro. 1. ed. Florianópolis: Empório do Direito, 2015.

CITRON, D. K.; FRANKS, M. A. Criminalizing Revenge Porn. The Wake Forest Law Review 345 (2014). Disponível em: <https://goo.gl/dWDxms>. Acesso em: 5 fev. 2014.

COMPROMISSO E ATITUDE. Lei Maria da Penha. A lei é mais forte. Disponível em: <https://goo.gl/6NiNZ4>. Acesso em: 20 maio 2017.

CYBER CIVIL RIGHTS INITIATIVE. 38 states + DC have revenge porn laws. Disponível em: $<$ https://goo.gl/shULwB>. Acesso em: 9 maio 2017.

DIAS, M. B. A Lei Maria da Penha na justiça: a efetividade da Lei 11.340/2006 de combate à violência doméstica e familiar contra a mulher. São Paulo: Editora Revista dos Tribunais, 2011.

FARIA, F. C. M.; ARAÚJO, J. S.; JORGE, M. F. Caiu na rede é porn: pornografia de vingança, violência de gênero e exposição da "intimidade". Contemporanea| Comunicação e Cultura. V. 13, n. 3, p. 659-667, set.-dez. 2015, p. 659-677. Disponível em: <https://goo.gl/B8GTMn>. Acesso em: 2 jul. 2017.

FERNANDES, V. D. S. Lei Maria da Penha: o processo penal no caminho da efetividade: abordagem jurídica e multidisciplinar. São Paulo: Atlas, 2015.

FOCAULT, M. A verdade e as formas jurídicas. Rio de Janeiro: Nau Ed, 1999.

FRANKS, M. A. Drafting an Effective "Revenge Porn” Law: A Guide for Legislators. 2015. Disponível em: <https://goo.gl/WfSMjx>. Acesso em: 1 maio 2015.

LINS, B. A. A internet não gosta de mulheres? Gênero, sexualidade, e violência nos debates sobre “pornografia de vingança”, 2015. Disponível em: <https://goo.gl/ScT49u>. Acesso em: 20 maio 2016.

MINISTÉRIO PÚBLICO DE SÃO PAULO. Ação Penal 0038488-38.2011.8.26.0002. Inquérito Policial 239/2011 - $3^{\mathrm{a}}$ Delegacia de Defesa da Mulher. Disponível em: <https://goo.gl/kPoiSw>. Acesso em: 1 maio 2017.

MORELLI, J.; AMIRTON, A.; MEIRELLES, F. S. L. Violência de gênero no século XXI: a pornografia de vingança. Revista da EMERJ, Rio de Janeiro, v. 18, n. 71, p. 88-93, nov./dez. 2015.

PORTO, A. A.; RICHTER, Daniela. O direito da criança e do adolescente e os riscos do cyberbullying e do sexting no ambiente digital: realidade ou exagero? In: XI Seminário Nacional Demandas Sociais e Políticas Públicas na Sociedade Contemporânea, 2015, Rio Grande do Sul. Anais... UNISC, 2015. Disponível em: <https://goo.gl/7A3M7X>. Acesso em: 12 maio 2017.

SAFFIOTI, H. O poder do macho. São Paulo: Editora Moderna, 1987.

SANTOS, B. S. Os tribunais nas sociedades contemporâneas. Porto: Edições Afrontamentos, 1996. 
SILVA, A. M. F.; SILVA, C. K. O problema da tipificação dos crimes informáticos: aspectos controversos a respeito da aplicação do artigo 154-a da Lei n 12.737/2012 “Lei Carolina Dieckmann” In: BORGES, P. C. C.; CARVALHO, E. M.; MELLO, M. M. P. (Coord.). Direito Penal, Processo Penal e Constituição II. Florianópolis: Conselho Nacional de Pesquisa e Pós-Graduação em Direito (Conpedi), 2014. Disponível em: <https://goo.gl/RW4pag>. Acesso em: 14 ago. 2016.

SILVA, A. S.; ALVES, J. M. A tipificação da "lesão à saúde psicológica”: revisitando o art. 129, do Código Penal à luz da Lei Maria da Penha. In: TEIXEIRA, J. P. A.; FREITAS, R. S.; VICTOR, S. A. F. (Coord.). Direitos e garantias fundamentais. Florianópolis: Conselho Nacional de Pesquisa e Pós-Graduação em Direito (Conpedi), 2016. Disponível em: <https://goo.gl/xDHQfi>. Acesso em: 12 maio 2017.

VALENTE, M. G. et al. O corpo é o código: estratégias jurídicas de enfrentamento ao revenge porn no Brasil. São Paulo: InternetLab, 2016.

Artenira da Silva e Silva

Pós-doutora em Psicologia e Educação pela Universidade do Porto. Doutora em Saúde Coletiva pela Universidade Federal da Bahia. Mestre em Saúde e Ambiente pela Universidade Federal do Maranhão. Graduada em Psicologia pela Pontifícia Universidade Católica de São Paulo. Docente e Pesquisadora no Departamento de Saúde Pública e no Programa de Pós-Graduação em Direito e Instituições do Sistema de Justiça/UFMA. Coordenadora de linha de pesquisa no Observatório Ibero Americano de Saúde e Cidadania e Coordenadora do Observatorium de Segurança Pública (PPGDIR-UFMA/CECGP). Psicóloga clínica e forense.E-mail: artenirasilva@hotmail.com

Rossana Barros Pinheiro Mestranda no Programa de Pós-Graduação em Direito e Instituições do Sistema de Justiça/UFMA. Graduada em Direito pela Universidade Federal do Maranhão. Membro da Equipe de Revisão da Revista do Curso de Direito. Membro do Núcleo de Estudos de Direito Constitucional. Bolsista da Capes. Advogada. E-mail: rossana.barros@hotmail.com 